\title{
Long peptic strictures of the esophagus due to reflux esophagitis: a case report
}

\author{
Yasushi Yamasaki, Soji Ozawa*, Junya Oguma, Akihito Kazuno and Yamato Ninomiya
}

\begin{abstract}
Background: Most of benign esophageal strictures caused by gastroesophageal reflux are short segments and can be treated by an endoscopic dilatation, but cases of long-segment stenosis requiring an esophagectomy are rare.

Case presentation: A 62-year-old woman had undergone emergency surgery for a giant ovarian tumor rupture at another hospital. A duodenal perforation occurred after surgery but improved with conservative treatment. She had undergone long-term nasogastric tube placement for 4 months because she was on a mechanical ventilator and did not receive proton pump inhibitors (PPIs). Thereafter, the patient experienced dysphagia. An esophagogastroduodenoscopy (EGD) revealed circumferential reflux esophagitis (grade D) and a stricture located 25 to $40 \mathrm{~cm}$ from the incisor teeth. She received medical treatment with fasting and PPIs. The second EGD revealed that the reflux esophagitis had improved somewhat, but that the esophageal stricture had worsened. Thereafter, balloon dilatation was attempted, but the stricture did not improve and she was referred to our hospital. Finally, she was diagnosed as having a benign esophageal stricture caused by reflux esophagitis. She underwent a thoracoscopic esophagectomy with gastric tube reconstruction through the antethoracic route. Her postoperative course was uneventful. Pathologically, a circumferential stricture with white scar formation and no malignant cells were observed.

Conclusions: We experienced a rare case requiring esophagectomy for long-segment stenosis caused by reflux esophagitis. It is suggested that the possibility of esophageal stricture needs to be kept in mind when treating GERD patients with long-term nasogastric tube placement.
\end{abstract}

Keywords: Reflux esophagitis, Stricture, Esophagectomy

\section{Background}

Many esophageal strictures are malignant, and benign esophageal strictures are not common. Most of benign esophageal strictures caused by gastroesophageal reflux are short segments and can be treated by an endoscopic dilatation [1], but cases of long-segment stenosis requiring an esophagectomy are rare. Here, we report a case of long-segment stenosis associated with reflux esophagitis and long-term nasogastric tube placement.

\section{Case presentation}

A 62-year-old woman had undergone emergency surgery for a giant ovarian tumor rupture at another hospital in December 2013. A duodenal perforation occurred after surgery but improved with conservative treatment. She

\footnotetext{
* Correspondence: sozawa@tokai.ac.jp

Department of Gastroenterological Surgery, Tokai University School of Medicine, 143 Shimokasuya, Isehara, Kanagawa 259-1193, Japan
}

had undergone long-term nasogastric tube placement for 4 months because she was on a mechanical ventilator and did not receive proton pump inhibitors (PPIs). Thereafter, the patient experienced dysphagia, and a video fluoroscopic examination of her swallowing revealed the reflux of contrast medium from the stomach to the esophagus in February 2014. An esophagogastroduodenoscopy (EGD) revealed circumferential reflux esophagitis (grade D) and a stricture located 25 to $40 \mathrm{~cm}$ from the incisor teeth. She received medical treatment with fasting and PPIs. She underwent an EGD again in March 2014. The reflux esophagitis had improved somewhat, but the esophageal stricture located $33 \mathrm{~cm}$ from the incisor teeth had worsened, making it difficult to pass the nasal endoscope. Thereafter, balloon dilatation was attempted, but the stricture did not improve and she was referred to our hospital in April 2014. She had a history of bronchial asthma. 
Upon admission, she had a height of $152.5 \mathrm{~cm}$, a weight of $41.6 \mathrm{~kg}$, a body mass index of 17.8 , a blood pressure of $108 / 58 \mathrm{mmHg}$, a temperature of $36.4{ }^{\circ} \mathrm{C}$, and pulse rate of 74 beats/minute, with no significant physical findings. Laboratory findings showed a hemoglobin level of $11.9 \mathrm{~g} / \mathrm{dL}$, a serum glutamic oxaloacetic transaminase level of $54 \mathrm{U} / \mathrm{L}$, and a serum glutamic pyruvic transaminase level of $119 \mathrm{U} / \mathrm{L}$, indicating mild anemia and liver dysfunction.

An upper gastrointestinal series revealed a severe stricture measuring $85 \mathrm{~mm}$ along the longitudinal axis from the middle to lower thoracic esophagus (Fig. 1). An EGD showed a cicatricial stricture beginning $25 \mathrm{~cm}$ from the incisor teeth, making it difficult to pass the endoscope through the esophagus (Fig. 2). A contrast-enhanced chest computed tomography $(\mathrm{CT})$ scan examination revealed marked wall thickening from the middle to lower thoracic esophagus (Fig. 3). FDG-PET/CT showed a slight accumulation of isotope in the esophagus, and while a malignant disease could not be completely ruled

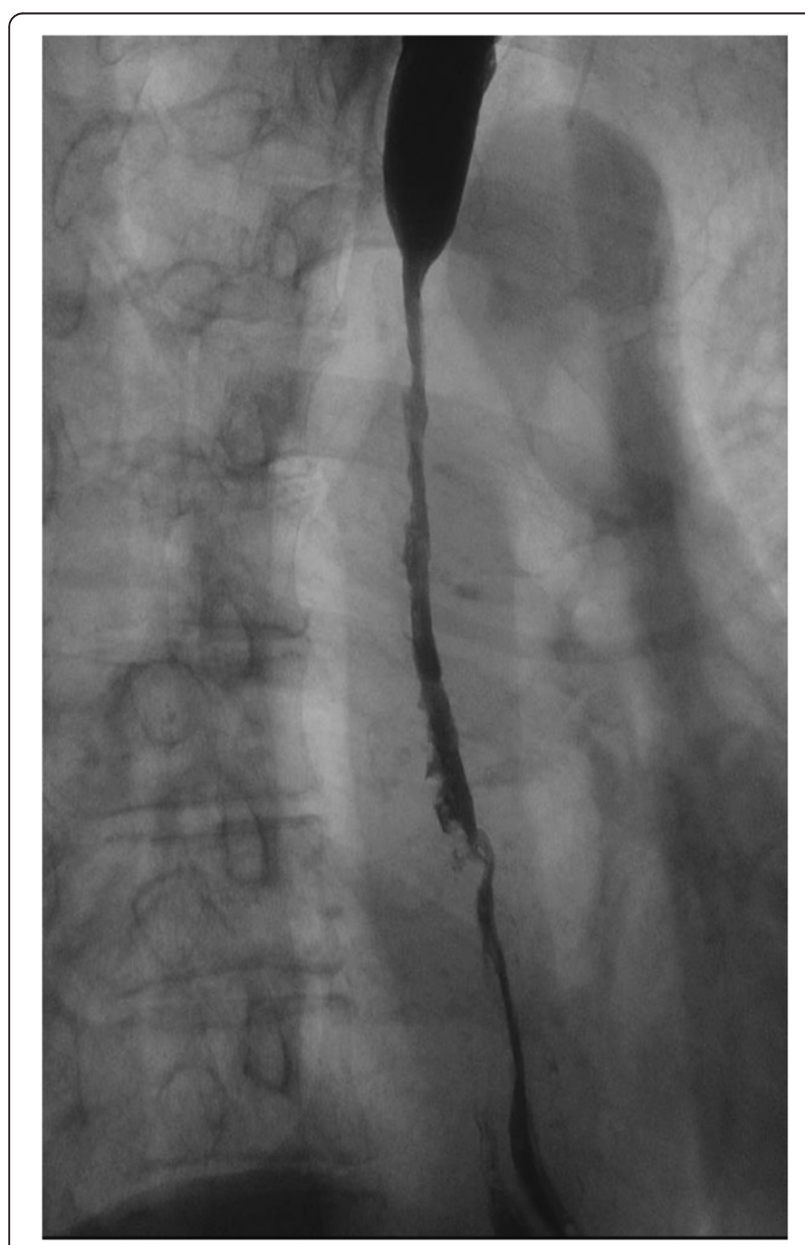

Fig. 1 Upper gastrointestinal series. A severe stricture measuring $85 \mathrm{~mm}$ along the longitudinal axis was observed extending from the middle to lower thoracic esophagus

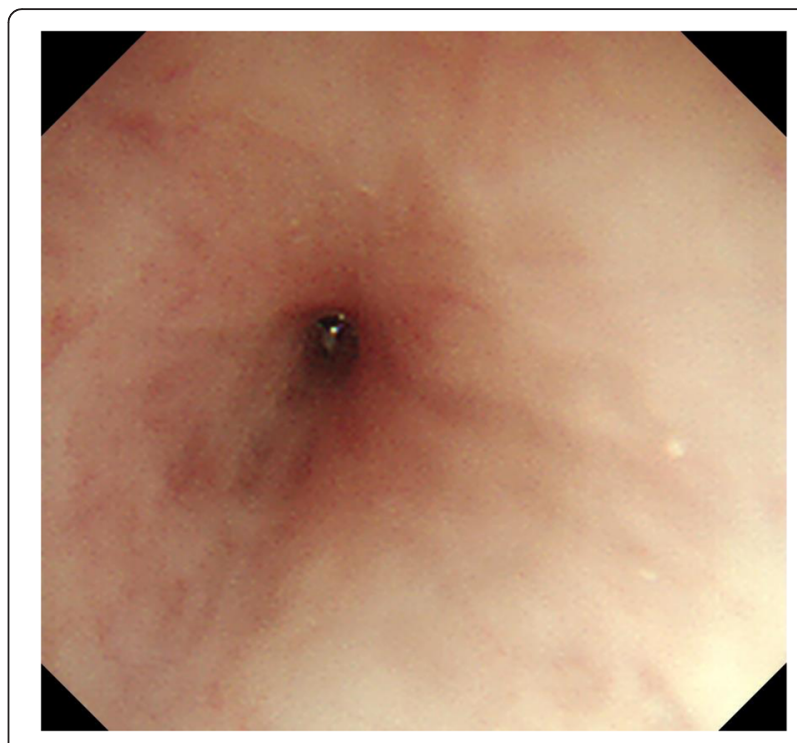

Fig. 2 Esophagogastroduodenoscopy. A cicatricial stricture beginning $25 \mathrm{~cm}$ from the incisor teeth was observed. The stricture made it difficult to pass a small-diameter scope through the esophagus

out, a diagnosis of esophagitis seemed more probable. Although a 24-h pH monitoring test is necessary for the diagnosis of gastroesophageal reflux disease (GERD), this test was not performed because the $\mathrm{pH}$ catheter was not expected to pass through the esophagus because of the severe stricture. The clinical course and the above findings led to a diagnosis of benign esophageal stricture caused by reflux esophagitis.

Because endoscopic balloon dilatation did not improve the stricture, a thoracoscopic esophagectomy was performed [2]. The patients were placed in a prone position after intubation using a single-lumen endotracheal tube and a bronchial blocker tube. Only the left lung was ventilated, and a pneumothorax in the right chest was created using $6 \mathrm{mmHg}$ of $\mathrm{CO}_{2}$ gas. Five trocars were inserted into the right thoracic cavity. The $12-\mathrm{mm}$ trocar inserted into the ninth intercostal space on the inferior scapular angle line was used for a flexible endoscope. The anterior pleura and the posterior pleura of the upper posterior mediastinum were incised around the esophagus, and the upper esophagus was mobilized. Lymph node dissection was not performed because the patient had been diagnosed as having a benign esophageal stricture. The arch of the azygos vein was divided, and the right bronchial artery was preserved. Next, the anterior pleura and the posterior pleura of the middle and lower posterior mediastinum were incised around the esophagus. When the middle and lower esophagus was also mobilized, a severe fibrotic change between the esophagus and the descending aorta was observed. This fibrotic change seemed to be similar to the change in a case that had received chemoradiation therapy (Fig. 4). 

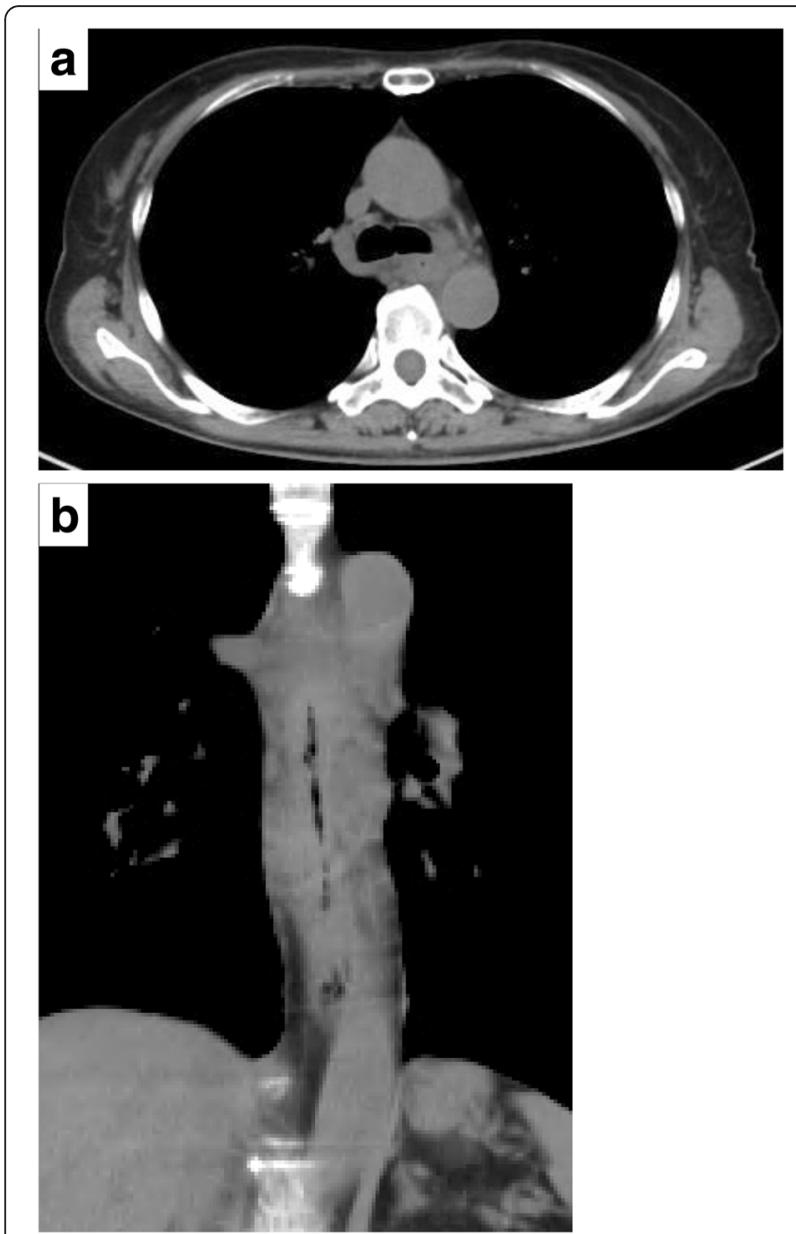

Fig. 3 Preoperative CT. a Transverse image. b Coronal image: marked thickening of the esophageal wall was observed from the middle to lower thoracic esophagus

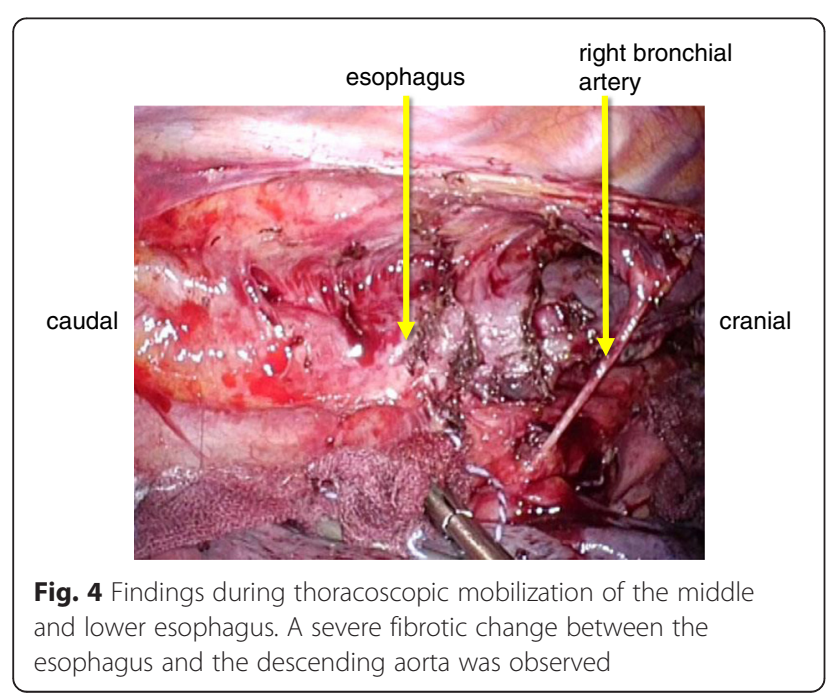

Finally, the upper esophagus was transected using a stapler device, and the thoracic esophagus was successfully mobilized. At the end of the thoracoscopic procedure, a single 32-Fr chest tube was inserted. The patient was then placed in a supine position. The stomach was mobilized, and a gastric tube was created. An antethoracic route was chosen because the patient had a BMI of
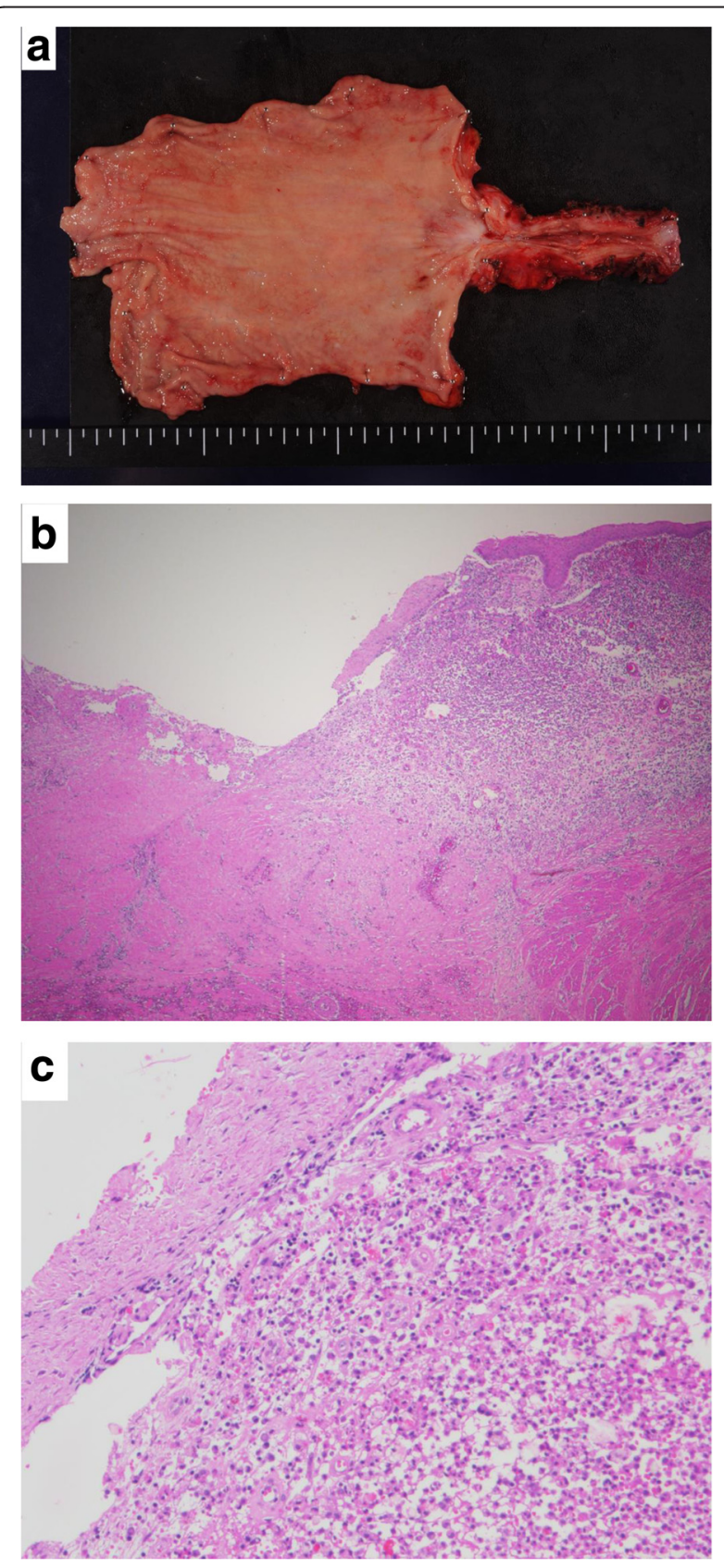

Fig. 5 Gross and microscopic findings. a Macroscopically, a long segment of circumferential thickening of the esophageal wall was observed. b Erosion and ulceration were visible (HE staining, $\times 20$ ). c Inflammatory cell infiltration was observed. No malignant findings were seen (HE staining, $\times 100)$ 
$17.8 \mathrm{~kg} / \mathrm{m}^{2}$ and was treated with total parenteral nutrition, which posed a surgical risk. An anastomosis between the cervical esophagus and the gastric tube was performed using a circular stapler in the neck, and a tube jejunostomy was created.

The gross pathological findings showed a circumferential stricture with white scar formation from the lower esophagus to the cardia. Histologically, the infiltration of inflammatory cells, mainly neutrophils, lymphocytes and plasma cells, and fibrosis were observed. Erosion and ulceration were seen, but there were no malignant findings (Fig. 5).

Her postoperative course was uneventful, and she was discharged on day 19. At present, 1 year and 8 months after surgery, she is attending an outpatient clinic.

\section{Discussion}

Esophageal strictures have a variety of causes. Makuuchi classified esophageal strictures into functional and organic strictures. The former included esophageal achalasia, diffuse spasm, vigorous achalasia, and nutcracker esophagus, while the latter included malignant neoplasms, reflux esophagitis, esophageal web, and postoperative anastomotic stricture. It was also described that most esophageal strictures caused by reflux esophagitis occur at the lower end of the esophagus [3]. The majority of esophageal strictures are malignant, and benign esophageal strictures are rare. Recently, the use of PPIs has decreased the number of patients with benign esophageal strictures. The incidence of esophageal stricture is 1.1 among 10,000 persons, and $68 \%$ of esophageal stricture cases are peptic. GERD, hernia, ulcer, and heavy drinking increase the risk of stricture [4]. Also, patients with esophagitis reportedly have an eight times higher risk of stricture [5].

The mechanism of stricture formation arising from reflux esophagitis is considered to be as follows: gastric acid reflux causes inflammation in the lamina propria which is then disrupted, leading to stricture formation
[6]. In addition, esophageal stricture caused by longterm nasogastric tube placement has also been reported, and according to the report, the use of a nasogastric tube for more than 2-4 weeks should be avoided [7]. The present patient had reflux esophagitis, had undergone long-term nasogastric tube placement, and did not receive PPIs, placing her at a high risk for stricture.

Malignant transformation has to be taken into account in esophageal strictures associated with reflux esophagitis. The reflux of digestive juice is widely known to cause the development of Barrett's esophagus, eventually leading to Barrett's esophageal cancer, and controlling the reflux of digestive juice to prevent malignant transformation is of primary importance. In this case, the clinical course and the findings of CT and FDG-PET/CT led to a diagnosis of benign esophageal stricture caused by reflux esophagitis. Postoperatively, the resected specimen revealed no malignant findings and the preoperative diagnosis was proven to be correct.

van Boeckel and Siersema previously described an algorithm for treatment selection. According to their report, endoscopic dilatation is successful in more than $80-90 \%$ of cases, but recurrence occurs within 1 year in one third of cases. At the time of recurrence, the combination of dilatation and steroid injection or stenting should be considered. Surgery should be a last-resort treatment option [8].

Surgery for benign esophageal stricture can be classified into two types. In cases where endoscopic dilatation can be performed, antireflux surgery, such as a Toupet, Belsey, or Nissen procedure, is performed following stricture dilatation. In cases where the stricture cannot be dilated, an esophagectomy and reconstruction are performed. In addition, surgery is indicated in (1) patients in whom stricture dilatation is not useful, (2) patients with frequent aphagia, (3) patients with intractable refractory esophagitis, and (4) patients with aspiration pneumonia, etc. [9]. In the present case, surgery was performed because the

Table 1 Reports of benign stricture caused by the gastroesophageal reflux

\begin{tabular}{|c|c|c|c|c|c|c|c|}
\hline No. & Author (year) & $n$ & $\begin{array}{l}\text { Age (years old) } \\
\text { (mean) }\end{array}$ & $\begin{array}{l}\text { Sex } \\
\text { (male:female) }\end{array}$ & $\begin{array}{l}\text { Mean length of } \\
\text { stricture }(\mathrm{mm})\end{array}$ & Cause of stricture & Treatment \\
\hline 1 & Rudstrom P (1954) [12] & 2 & 49.5 & $2: 0$ & 45 & Peptic stricture & 2: surgical \\
\hline \multirow[t]{2}{*}{2} & \multirow[t]{2}{*}{ Raptis S (1972) [13] } & \multirow[t]{2}{*}{100} & \multirow[t]{2}{*}{69} & \multirow[t]{2}{*}{$30: 70$} & \multirow[t]{2}{*}{ 10-70(range) } & \multirow[t]{2}{*}{ Peptic stricture (most cases) } & 50: surgical \\
\hline & & & & & & & 50: non-surgical \\
\hline \multirow[t]{2}{*}{3} & \multirow[t]{2}{*}{ Jaffray B (1998) [14] } & \multirow[t]{2}{*}{113} & \multirow[t]{2}{*}{67} & \multirow[t]{2}{*}{$63: 50$} & \multirow[t]{2}{*}{ 20-50(range) } & \multirow[t]{2}{*}{ Peptic stricture } & 13: surgical \\
\hline & & & & & & & 100: non-surgical \\
\hline \multirow[t]{2}{*}{4} & \multirow[t]{2}{*}{ Braghetto I (2002) [15] } & \multirow[t]{2}{*}{185} & \multirow[t]{2}{*}{64.1} & \multirow[t]{2}{*}{$135: 50$} & \multirow[t]{2}{*}{$25.1 \pm 11$} & \multirow[t]{2}{*}{ Peptic stricture } & 170: surgical \\
\hline & & & & & & & 15: non-surgical \\
\hline 5 & Qureshi S (2010) [16] & 10 & 10 & $3: 7$ & $39 \pm 17$ & Peptic stricture & Not described \\
\hline Present case & Yamasaki Y (2015) & 1 & 62 & $0: 1$ & 85 & Peptic stricture & 1: surgical \\
\hline
\end{tabular}


patient was refractory to endoscopic treatment and had reflux esophagitis (grade D), and the extended length of the stricture persisted even after conservative treatment.

The present case was characterized by an $85-\mathrm{mm}$-long segment of stenosis extending from the middle to lower thoracic esophagus. As described above, most strictures associated with reflux esophagitis are usually localized at the lower end of the lower esophagus and are found at a distance of 1 to $4 \mathrm{~cm}$ from the gastroesophageal junction $[10,11]$. A search of PubMed using the keywords "esophagus," "stricture," and "benign" yielded five articles on benign stricture caused by the reflux of digestive juice describing the length of the stricture [12-16] (Table 1). None of the severe strictures measured $>8 \mathrm{~cm}$ in length in these reports. Accordingly, the present case appears to be relatively rare.

\section{Conclusions}

We experienced a case requiring esophagectomy for long-segment stenosis caused by reflux esophagitis. It is suggested that the possibility of esophageal stricture needs to be kept in mind when treating GERD patients with long-term nasogastric tube placement.

\section{Consent for publication}

Written informed consent was obtained from the patient for publication of this case report and any accompanying images.

\section{Abbreviations \\ $C T$, computed tomography; GERD, gastroesophageal reflux disease; PPIs, proton pump inhibitors.}

\section{Competing interests}

The authors declare that they have no competing interests.

\section{Authors' contributions}

YY, SO, JO, and AK underwent the operation. YY and SO have made substantial contributions to the conception and design of the case report. All authors read and approved the final manuscript.

\section{Authors' information}

YY and AK are Assistant Professor of Department of Gastroenterological Surgery, Tokai University School of Medicine. SO is a Professor of Department of Gastroenterological Surgery, Tokai University School of Medicine. JO is a Junior Assistant Professor of Department of Gastroenterological Surgery, Tokai University School of Medicine. YN is a student of Tokai University Graduate School of Medicine.

Received: 16 March 2016 Accepted: 17 June 2016

Published online: 25 June 2016

\section{References}

1. Matsumoto A, Omura N, Ishibashi Y, Suzuki Y, Nakada K, Kashiwagi H, et al. Esophageal stricture caused by reflux esophagitis requiring subtotal esophagectomy: case report. Esophagus. 2007;4:185-8.

2. Ozawa S, Ito E, Kazuno A, Chino O, Nakui M, Yamamoto S, et al. Thoracoscopic esophagectomy while in a prone position for esophageal cancer: a preceding anterior approach method. Surg Endosc. 2013;27:40-7.

3. Makuuchi H. Points to consider in differential diagnosis of stenotic disease in the esophagus. Endoscopia Digestiva. 2014;26:1720-3.
4. Ruigómez A, García Rodríguez LA, Wallander MA, Johansson S, Eklund S. Esophageal stricture: incidence, treatment patterns, and recurrence rate. Am J Gastroenterol. 2006;101:2685-92.

5. Hvid-Jensen F, Pedersen L, Munk EM, Drewes AM, Funch-Jensen P. Longterm complications to reflux disease in community practice. A 17-year cohort study of 4706 patients. Scand J Gastroenterol. 2011;46:1179-86.

6. Awad ZT, Filipi CJ, Mittal SK, Roth TA, Marsh RE, Shiino Y, et al. Left side thoracoscopically assisted gastroplasty: a new technique for managing the shortened esophagus. Surg Endosc. 2000;14:508-12.

7. Yoo IK, Chun HJ, Keum B. Unusual shape of esophageal stricture after use of nasogastric tube. Clin Gastroenterol and Hepatol. 2015;13:e141-2.

8. van Boeckel PGA, Siersema PD. Refractory esophageal strictures: what to do when dilation fails. Curr Treat Options in Gastroenterol. 2015;13:47-58.

9. Kuo WH, Kalloo AN. Reflux strictures of the esophagus. Gastrointest Endosc Clin N Am. 1998:8:273-81.

10. Stein HJ, Barlow AP, Demeester TR, Hinder RA. Complications of gastroesophageal reflux disease. Role of the lower esophageal sphincter, esophageal acid and acid/alkaline exposure, and duodenogastric reflux. Ann Surg. 1992;216:35-43.

11. Marks RD, Richter JE. Peptic strictures of the esophagus. Am J Gastroenterol. 1993;88:1160-73.

12. Rudstrom P. Benign esophagus strictures caused by reflux esophagitis in cases of duodenal ulcer. Acta Chir Scand. 1954;107:404-13.

13. Raptis S, Milne DM. A review of the management of 100 cases of benign stricture of the oesophagus. Thorax. 1972;27:599-603.

14. Jaffray B, Anderson JR. A patient's perspective on the management of peptic esophageal stricture: experience and results in 113 consecutive cases. Dis Esophagus. 1998;11:109-15.

15. Braghetto I, Csendes A, Burdiles P, Korn O, Compan A, Guerra JF. Barrett's esophagus complicated with stricture: correlation between classification and the results of the different therapeutic options. World J Surg. 2002;26:1228-33.

16. Qureshi S, Ghazanfar S, Leghari A, Tariq F, Niaz SK, Quraishy MS. Benign esophageal strictures: behaviour, pattern and response to dilatation. J Pak Med Assoc. 2010;60:656-60.

\section{Submit your manuscript to a SpringerOpen ${ }^{\circ}$ journal and benefit from:}

- Convenient online submission

- Rigorous peer review

- Immediate publication on acceptance

- Open access: articles freely available online

- High visibility within the field

- Retaining the copyright to your article

Submit your next manuscript at springeropen.com 